Acta Genet Med Gemellol 39:109-115 (1990)

(C)1990 by The Mendel Institute, Rome

Sixth International Congress

on Twin Studies

\title{
Zygosity Diagnosis of Twins by Questionnaire
}

\author{
S. Ooki ${ }^{1}$, K. Yamada ${ }^{2}$, A. Asaka ${ }^{3}$, K. Hayakawa ${ }^{4}$
}

${ }^{1}$ School of Health Sciences, Faculty of Medicine, University of Tokyo; ${ }^{2}$ Department of Nursing, Sapporo Medical College; ${ }^{3}$ Department of Health Sciences, Yamanashi Medical College; ${ }^{4}$ Department of Public Health, School of Medicine, Kinki University, Osaka, Japan

\begin{abstract}
Subjects were 189 twin pairs, $165 \mathrm{MZ}$ and 24 same-sexed DZ, who entered the junior high school affiliated to Tokyo University (sample T), and 93 twin pairs, $71 \mathrm{MZ}$ and 22 same-sexed DZ, who were registered at Kinki University (sample K). The zygosity was previously identified by many genetic markers, and this study aimed at zygosity diagnosis by questionnaire. The latter included three questions: "How are you alike?", "How often are you mistaken?", and "By whom are you mistaken?". According to the degree, 1-3 points, 1-3 points, and 1-4 points were given for each question, and the sum of the points of each pair of twins was calculated. Zygosity was determined by the sum of points, distributed from 6 to 20. Namely, if the sum was 6-13, the twin pair was considered MZ, and if the sum was 14-20, DZ. More than $90 \%$ of twins were diagnosed correctly by use of this cutting point. This result was in accordance with that obtained by use of discriminant function analysis. It is concluded that zygosity diagnosis by questionnaire is convenient and useful, in particular for epidemiological research.
\end{abstract}

Key words: Zygosity diagnosis, Questionnaire, Discriminant function analysis

A great number of genetic markers, such as blood groups, is needed in order to establish an accurate zygosity diagnosis. It is desirable, however, to spare time and money in cases where many twins must be dealt with. The effectiveness of zygosity diagnosis by simple questionnaire has been reported many times [1-12]. The questionnaire used in this study is presented in Table 1. It is translated into Japanese from an original report by Torgersen [12]. The questionnaire consists of three questions: "How are you alike?", "How often are you mistaken?", and "By 
whom are you mistaken?". This study aims at clarifying the effectiveness of this questionnaire in a Japanese sample.

Table 1 - The questionnaire

Below you will find three questions about how alike you and your $t$ win were in childhood. Please mark off the answers which are most fitting.

1. Were you and your twin "as alike as two peas in a pod?"

1 As alike as two peas in a pod

2 Usual sibs similarity

3 Quiete different

2. Were you and your twin mixed up as children?

1 Yes, very often

2 Now and then

3 Never

3. In that case, by whom were you mixed up?

1 Parents

2 Teachers

3 Others

4 Nobody

\section{MATERIALS AND METHODS}

The subjects analysed formed two samples of same-sexed twin pairs. Their zygosity was determined by many genetic markers.

Subjects of the first sample were 189 same-sexed twin pairs, $165 \mathrm{MZ}$ and 24 $\mathrm{DZ}$ who entered the junior high school affiliated to the Tokyo University from 1976 to 1989 , aged 12 to 16 (sample $\mathrm{T}$ ) [10]. The genetic markers used for their zygosity diagnosis were as follows: AB0, MN, Rh, Se, P, Duffy, HLA, Hp, Tf, Gc, Gm, Km, Pi, GPT, PGM, ACP, ESD, PGD, ADA, and others.

Subjects of the second sample were 93 twin pairs, $71 \mathrm{MZ}$ and $22 \mathrm{DZ}$, who were registered at Kinki University (sample K) [5]. They were adult twins, aged 50 to 77. The genetic markers used for zygosity diagnosis were AB0, MN, Rh, Lewis, $\mathrm{P}$, Duffy, Kell, Diego and PTC tasting.

None of the subjects knew their zygosity when they were asked to answer the questionnaire. At first, the patterns of answers for three questions of A (elder brother or sister) and B (younger brother or sister) were examined separately for $\mathrm{MZ}$ and $\mathrm{DZ}$. In the next place, according to the degree of the similarity, 1-3 or 1-4 points were given for each question. That is: the answers "As like as two peas in a pod", "Mixed up very often" and "Mixed up by parents" were given the score 1; "Usual sib-similarity", "Mixed up now and then" and "Mixed up by teachers", the score 2; "Quite different", "Never mixed up" and "Mixed up by others", the score 3; and "Mixed up by nobody", the score 4. The scores for both twins were summed up, so as to distribute from 6 to 20 . The distribution of the scores was tested separately for $\mathrm{MZ}$ and $\mathrm{DZ}$ pairs, and the cutting point which distinguishes MZ from DZ pairs most effectively was examined. 
Moreover "discriminant function analysis" was carried out. In this case discriminant function was calculated at first for each sample as an "initial sample", then this function was applied for the other sample as a "follow-up sample". In this way the validity of the discriminant function was assessed.

Lastly, a comparison between the diagnosis by the raw scores and that by the discriminant function was performed.

Table 2 - Answers about similarity in childhood (Question 1)

\begin{tabular}{|c|c|c|c|c|c|c|c|}
\hline \multicolumn{8}{|c|}{ Sample $\mathbf{T}$} \\
\hline \multicolumn{4}{|c|}{$M Z$ pairs $(N=165)$} & \multicolumn{4}{|c|}{$D Z$ pairs $(N=24)$} \\
\hline \multicolumn{4}{|c|}{ Twin A } & \multirow[b]{2}{*}{ Twin B } & \multicolumn{3}{|c|}{ Twin $A$} \\
\hline Twin B & 1 & 2 & $\overline{3}$ & & 1 & 2 & 3 \\
\hline 1 & 98 & 19 & 0 & 1 & 1 & 0 & 0 \\
\hline 2 & 8 & 37 & 2 & 2 & 0 & 7 & 2 \\
\hline 3 & 0 & 1 & 0 & 3 & 0 & 2 & 12 \\
\hline \multicolumn{8}{|c|}{ Sample K } \\
\hline \multicolumn{4}{|c|}{$\mathrm{MZ}$ pairs $(\mathrm{N}=71)$} & \multicolumn{4}{|c|}{ DZ pairs $(N=22)$} \\
\hline \multicolumn{4}{|c|}{ Twin A } & \multirow[b]{2}{*}{ Twin B } & \multicolumn{3}{|c|}{ Twin A } \\
\hline Twin B & 1 & 2 & 3 & & $\overline{1}$ & 2 & 3 \\
\hline 1 & 68 & 2 & 0 & 1 & 1 & 3 & 0 \\
\hline 2 & 1 & 0 & 0 & 2 & 1 & 8 & 1 \\
\hline 3 & 0 & 0 & 0 & 3 & 0 & 2 & 6 \\
\hline
\end{tabular}

Table 3 - Answers about mixing up in childhood (Question 2)

Sample $\mathbf{T}$

\begin{tabular}{|c|c|c|c|c|c|c|c|}
\hline \multicolumn{4}{|c|}{$M Z$ pairs $(N=165)$} & \multicolumn{4}{|c|}{$D Z$ pairs $(N=24)$} \\
\hline \multicolumn{4}{|c|}{ Twin A } & \multirow[b]{2}{*}{ Twin $B$} & \multicolumn{3}{|c|}{ Twin A } \\
\hline Twin B & 1 & 2 & 3 & & 1 & 2 & 3 \\
\hline 1 & 62 & 15 & 0 & 1 & 0 & 0 & 1 \\
\hline 2 & 22 & 63 & 1 & 2 & 0 & 7 & 1 \\
\hline 3 & $\mathbf{0}$ & 1 & 1 & 3 & 0 & 2 & 13 \\
\hline
\end{tabular}

Sample $\mathbf{K}$

\begin{tabular}{|c|c|c|c|c|c|c|c|}
\hline \multicolumn{4}{|c|}{ MZ pairs $(N=71)$} & \multicolumn{4}{|c|}{ DZ pairs $(N=22)$} \\
\hline & & in & & & & wi & \\
\hline Twin B & 1 & 2 & 3 & Twin B & 1 & 2 & 3 \\
\hline 1 & 52 & 6 & 0 & 1 & 1 & 1 & 0 \\
\hline 2 & 3 & 8 & 0 & 2 & $\mathbf{0}$ & 3 & 2 \\
\hline 3 & 1 & 1 & 0 & 3 & 0 & 2 & 13 \\
\hline
\end{tabular}




\section{Ooki et al.}

Table 4 - Answers about who mixed up the twins (Question 3)

\begin{tabular}{|c|c|c|c|c|c|c|c|c|c|}
\hline \multicolumn{10}{|c|}{ Sample T } \\
\hline \multicolumn{5}{|c|}{ MZ pairs $(N=165)$} & \multicolumn{5}{|c|}{ DZ pairs $(N=24)$} \\
\hline \multicolumn{5}{|c|}{ Twin $\mathrm{A}$} & \multirow[b]{2}{*}{ Twin B } & \multicolumn{4}{|c|}{ Twin A } \\
\hline Twin B & $\overline{1}$ & 2 & 3 & $\overline{4}$ & & $\overline{1}$ & 2 & 3 & 4 \\
\hline $\mathbf{1}$ & 9 & 3 & 0 & 0 & 1 & 0 & $\mathbf{0}$ & 0 & 0 \\
\hline 2 & 2 & 65 & 22 & 0 & 2 & 0 & 2 & $\mathbf{0}$ & 1 \\
\hline 3 & 0 & 11 & 51 & 1 & 3 & 0 & $\mathbf{0}$ & 5 & 1 \\
\hline 4 & 0 & 0 & 0 & 1 & 4 & 1 & 0 & 1 & 13 \\
\hline \multicolumn{10}{|c|}{ Sample K } \\
\hline \multicolumn{5}{|c|}{ MZ pairs $(N=71)$} & \multicolumn{5}{|c|}{ DZ pairs $(N=22)$} \\
\hline & \multicolumn{4}{|c|}{ Twin A } & & \multicolumn{4}{|c|}{ Twin A } \\
\hline Twin B & 1 & 2 & 3 & $\overline{4}$ & Twin B & $\overline{1}$ & 2 & 3 & 4 \\
\hline 1 & 1 & 4 & $\mathbf{1}$ & 0 & 1 & 0 & $\mathbf{0}$ & 0 & 0 \\
\hline 2 & 3 & 22 & 9 & 0 & 2 & 0 & 2 & 1 & 0 \\
\hline 3 & 0 & 4 & 27 & 0 & 3 & 0 & 0 & 4 & 0 \\
\hline 4 & 0 & 0 & 0 & 0 & 4 & 0 & 0 & 2 & 13 \\
\hline
\end{tabular}

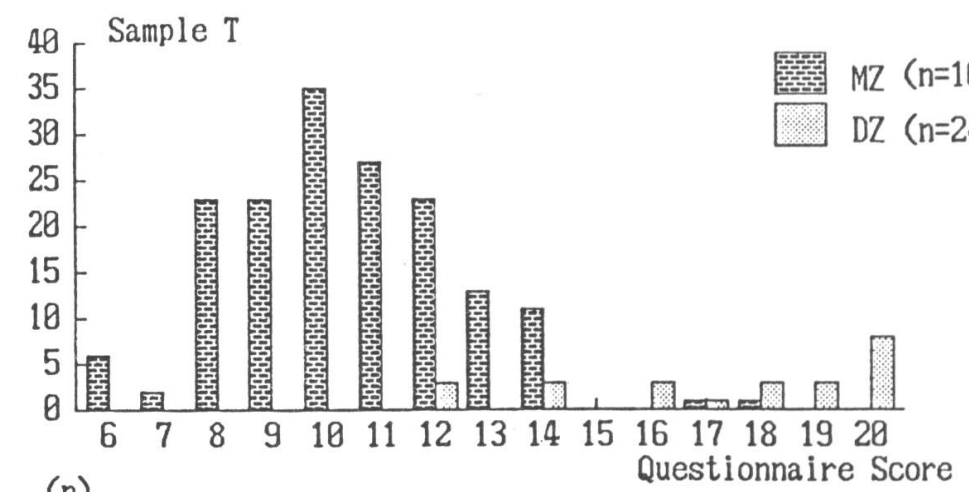

(n)

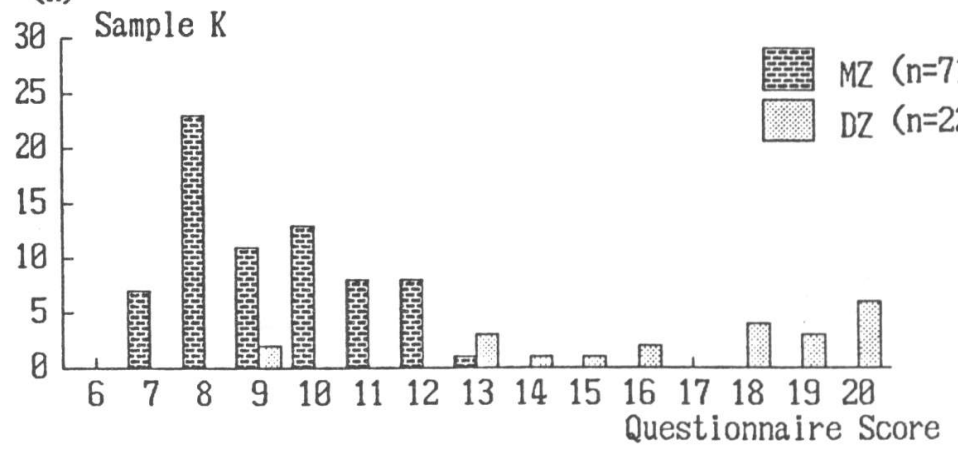

Figure. Distribution of questionnaire score for $\mathrm{MZ}$ and $\mathrm{DZ} \mathrm{t}$ win pairs. 


\section{RESULTS}

The answers of the twins are summarized in Tables 2,3 , and 4 separately for the three questions. For question 1, the highest percentage of $\mathrm{MZ}$ twins both answered "As like as two peas in a pod". If pairs where one or both twins answered to be "As like as two peas in a pod" were considered to be MZ and the rest DZ (criteria A), 148 of $189(78.3 \%$ ) were diagnosed correctly in sample $T$, and 88 of $93(94.6 \%)$ in sample $\mathrm{K}$. For question 2, an almost equal percentage of $\mathrm{MZ}$ twins in sample $T$ both answered "Mixed up very often" and "Mixed up now and then", whereas in sample $\mathrm{K}$ most twins answered "Mixed up very often". If pairs where one or both twins answered to be "Mixed up very often" were considered to be MZ and the rest DZ (criteria B), the pairs diagnosed correctly were 122 of $189(64.6 \%)$ in sample T, and 82 of $93(88.2 \%)$ in sample $\mathrm{K}$. As for question 3 , the answers of MZ pairs appeared to concentrate in moderate points, whereas those of DZ pairs in high points.

The distribution of the raw scores is shown in the Figure. The scores of MZ pairs of sample $\mathrm{T}$ are distributed from 6 to 18 , and those of $\mathrm{DZ}$ pairs from 12 to 20. The $\mathrm{MZ}$ scores of sample $\mathrm{K}$ are distributed from 7 to 13 , and the $\mathrm{DZ}$ scores from 9 to 20 . The difference between zygosity groups was clearly recognized in both samples. MZ pairs with raw scores equal to, or less than 13 were $92.1 \%(152 / 165)$ in sample $\mathrm{T}$, and $100 \%(71 / 71)$ in sample $\mathrm{K}$. DZ pairs with raw scores $\geq 14$ were $87.5 \%(21 / 24)$ in sample $\mathrm{T}$ and $77.3 \%(17 / 22)$ in sample $\mathrm{K}$.

Table 5 - Diagnosis by discriminant function analysis (each sample as an initial sample)

\begin{tabular}{|c|c|c|c|c|}
\hline \multirow[b]{2}{*}{ Zygosity } & \multirow[b]{2}{*}{$\mathbf{N}$} & \multicolumn{3}{|c|}{ Zygosity according to questionnaire } \\
\hline & & MZ & & $\overline{\mathrm{DZ}}$ \\
\hline \multicolumn{5}{|c|}{ Sample T } \\
\hline MZ & 165 & $152(92.1 \%)$ & 13 & $(7.9 \%)$ \\
\hline DZ & 24 & $3(12.5 \%)$ & 21 & $(87.5 \%)$ \\
\hline \multicolumn{5}{|c|}{ Correctly diagnosed: $173 \quad(91.5 \%)$} \\
\hline \multicolumn{5}{|c|}{ Discriminant function $^{a}: y=0.64967 x_{1}+0.42073 x_{2}+0.30421 x_{3}-4.85247$} \\
\hline \multicolumn{5}{|c|}{ Standard discriminant function coefficients: $x_{1}: 0.59433, x_{2}: 0.39108, x_{3}: 0.35742$} \\
\hline \multicolumn{5}{|c|}{ Sample K } \\
\hline MZ & 71 & $67(94.4 \%)$ & 4 & $(5.6 \%)$ \\
\hline DZ & 22 & $(9.1 \%)$ & 20 & $(90.9 \%)$ \\
\hline \multicolumn{5}{|c|}{ Correctly diagnosed: $87 \quad(93.5 \%)$} \\
\hline \multicolumn{5}{|c|}{ Discriminant function $^{a}: y=1.21543 x_{1}+0.58941 x_{2}-0.14121 x_{3}-4.22703$} \\
\hline \multicolumn{5}{|c|}{ Standard discriminant function coefficients: $x_{1}: 0.74502, x_{2}: 0.51394, x_{3}:-0.16455$} \\
\hline
\end{tabular}

a $x_{1}, x_{2}, x_{3}$ indicate scores of questions $1,2,3$, respectively. 


\section{Ooki et al.}

The discriminant function analysis of each "initial sample" indicated that $91.5 \%(173 / 189)$ of pairs in sample $\mathrm{T}$, and $93.5 \%(87 / 93)$ of pairs in sample $\mathrm{K}$ were diagnosed correctly (see Table 5 ). MZ pairs were more correctly diagnosed than DZ pairs. The standardized discriminant function coefficient of question 1 was the highest, suggesting that this question contributed the most among the three questions. If the discriminant function obtained by sample $\mathrm{T}$ was applied for sample $\mathrm{K}$, the correct diagnosis was $94.6 \%(88 / 93)$. When the discriminant function from sample $\mathrm{K}$ was applied for sample $\mathrm{T}, 67.2 \%(127 / 189)$ of the sample $\mathrm{T}$ was diagnosed correctly (see Table 6).

Table 6 - Diagnosis by discriminant function analysis (each sample as a follow-up sample)

\begin{tabular}{|c|c|c|c|c|}
\hline \multirow[b]{2}{*}{ Zygosity } & \multirow[b]{2}{*}{$\mathbf{N}$} & \multicolumn{3}{|c|}{ Zygosity according to questionnaire } \\
\hline & & $\mathrm{MZ}$ & & $\mathrm{DZ}$ \\
\hline \multicolumn{5}{|c|}{ Sample $T$ as an initial sample and sample $K$ as a follow-up sample } \\
\hline $\mathrm{MZ}$ & 71 & $71 \quad(100.0 \%)$ & 0 & $(0.0 \%)$ \\
\hline DZ & 22 & $5 \quad(22.7 \%)$ & 17 & $(77.3 \%)$ \\
\hline Correctly diagnosed: 88 & $(94.6 \%)$ & & & \\
\hline
\end{tabular}

Sample $K$ as an initial sample and sample $T$ as a follow-up sample

$\begin{array}{lrrrrr}\text { MZ } & 165 & 104 & (63.0 \%) & & 61 \\ \text { DZ } & 24 & 1 & (4.2 \%) & & (37.0 \%) \\ \end{array}$

Correctly diagnosed: $127 \quad(67.2 \%)$

\section{DISCUSSION}

Answers to questions 1 and 2 of the questionnaire concentrated in low scores for MZ twins and higher scores for $\mathrm{DZ}$ twins in both samples. This tendency was more obvious in adult MZ twins (sample $\mathrm{K}$ ), possibly because the difference between MZ cotwins become more and more recognized as they grow up, so they may emphasize their close resemblance in their childhood.

Torgersen [12] reported that more than $90 \%$ of twin pairs were classified correctly only by question 1 (criteria $A$ ) or 2 (criteria $B$ ). But our study did not support this result, especially when sample $T$ (school children) was examined, possibly because Torgersen's subjects were adult twins. It may be important to consider the age of the subjects when zygosity diagnosis by questionnaire is carried out.

In the next place, the MZ summed up scores of the K sample were significantly lower than those of the $T$ sample by the Median Test $(P<0.01)$, which may be due to the different age of the subjects. In spite of such difference, nearly the same ranges of summed up raw scores were found in $\mathrm{MZ}$ and $\mathrm{DZ}$ pairs in both samples. If the cutting point between $\mathrm{MZ}$ and $\mathrm{DZ}$ pairs is set between 13 and 14, the zygosity 
diagnosis is most effectively made.

The result of discriminant function analysis showed that more than $90 \%$ of twins were correctly diagnosed and that question 1 was the most effective one. The result of discriminant function analysis was nearly the same as that obtained by the method of raw scores. In validating the discriminant function, many MZ pairs of the $\mathrm{T}$ sample were misclassified by using the discriminant function obtained by the $\mathrm{K}$ sample, because of the latter's closer resemblance.

The analysis by use of the raw scores and the discriminant function was also carried out separately for males and females, but no difference was found.

The findings from this study show that this questionnaire can be effective in determining zygosity and simple enough to use practically. The cutting point between $M Z$ and $D Z$ pairs is of course flexible. If more accurate diagnosis is demanded, the zygosity of pairs who show intermediate scores, eg, 13 and 14, should be confirmed.

\section{REFERENCES}

1. Cederlöf R, Friberg L, Jonsson E, et al (1961): Studies on similarity diagnosis in twins with the aid of mailed questionnaires. Acta Genet 11:338-362.

2. Cohen DJ, Dibble E, Grawe JM, et al (1973): Separating identical from fraternal twins. Arch Gen Psychiatry 29:465-469.

3. Cohen DJ, Dibble E, Grawe JM, et al (1975): Reliably separating identical from fratemal twins. Arch Gen Psychiatry 32:1371-1375.

4. Eisen S, Neuman R, Goldberg J, et al (1989): Determining zygosity in the Vietnam Era Twin Registry: An approach using questionnaires. Clin Genet 35:423-432.

5. Hayakawa K, Shimizu T, Ohkuni M (1983): Gerontological research on aging twins (Second Report). Jpn J Pub Hlth 30:349-357.

6. Jablon S, Neer J, Gershowitz H, et al (1967): The NAS-NRC Twin Panel: Method of construction of the panel, zygosity diagnosis, and proposed use. Am J Hum Genet 19:133161.

7. Kasriel J, Eaves L (1976): The zygosity of twins: Further evidence on the agreement between diagnosis by blood groups and written questionnaires. J Biosoc Sci 8:263-266.

8. Magnus P, Berg K, Nance WE (1983): Predicting zygosity in Norwegian twin pairs born 1915-1960. Clin Genet 24:103-112.

9. Nichols RC, Bilbro WC (1966): The diagnosis of twin zygosity. Acta Genet 16:265-275.

10. Ooki S, Asaka A, Yamada K (1988): Zygosity diagnosis of twins by questionnaire. Jpn J Hum Genet 34:70.

11. Sarna S, Kaprio J, Sistonen P, et al (1978): Diagnosis of twin zygosity by mailed questionnaire. Hum Hered 28:241-254.

12. Torgersen $S$ (1979): The determination of $t$ win zygosity by means of a mailed questionnaire. Acta Genet Med Gemellol 28:225-236.

Correspondence: S. Ooki, Department of Mental Health, School of Health Sciences, Faculty of Medicine, The University of Tokyo, 7-3-1 Hongo, Bunkyo-ku, Tokyo 113, Japan. 